\title{
ORBITER GLOW OBSERVATIONS AT HIGH SPECTRAL RESOLUTION
}

\author{
David J.W. Kenda11 and Richard L. Gattinger \\ Herzberg Institute of Astrophysics \\ National Research Council of Canada \\ Edward J. Llewellyn and Ian C. McDade \\ Institute of Space and Atmospheric Studies \\ University of Saskatchewan \\ Steven B. Mende \\ Lockheed Palo Alto Research Laboratory
}

\begin{abstract}
An experiment flown on mission STS $41-G$ as part of the Canadian complement of experiments was designed to obtain relatively high resolution spectra of the Orbiter glow phenomenon over limited spectral regions centered on prominent upper atmospheric emissions. Observations were carried out successfully at altitudes of $360 \mathrm{~km}$ and $230 \mathrm{~km}$ although those at the lower altitude were limited by degradation of the image intensifier. Definitive glow results were obtained at the end of a thruster firing which showed the spectrum to be a continuum at a resolution of approximately $0.4 \mathrm{~nm}$ centered at a wavelength of $630 \mathrm{~nm}$. Results at other wavelengths in the absence of any firings strongly suggest that the Orbiter glow is a continuum throughout the spectral region $550 \mathrm{~nm}$ to $760 \mathrm{~nm}$. A discussion is presented that considers the reaction $\mathrm{NO}+\mathrm{O}_{2}{ }^{*}$ as being a possible candidate for the mechanism producing the shuttle glow.
\end{abstract}

\section{Introduction}

In 1984, an opportunity arose to fly a complement of experiments onboard the shuttle to be performed by a Canadian payload specialist. One of the experiments accepted for flight was given the acronym OGLOW and consisted of an imaged intensified camera system onto which was attached a series of filters or a transmission grating spectrograph. The filters were selected to be centered on prominent atmospheric emissions of interest to the WAMDII (Wide Angle Michelson Doppler Imaging Interferometer) instrument that will be flown onboard the shuttle in 1989 [Shepherd et al., 1985]. The purpose of the OGLOW experiment was to obtain relatively high spectral resolution images of the Orbiter glow phenomenon and of the selected atmospheric emissions in order to provide knowledge of these emissions from above the atmospheric source region and to provide quantitative values of the shuttle glow intensity and spectral shape at these wavelengths.

The OGLOW experiment was flown successfully on mission 41-G in October 1984 and produced results both of the glow phenomenon and of atmospheric emissions. Further details on the instrument and the varied scientific objectives may be found in Kendall et al. [1985]. 


\section{Observations}

For the STS 41-G flight, narrow bandpass interference filters $(0.4$ $\mathrm{nm}$ ) were employed with a central wavelength, for normal incidence, slightly longer than that of the atmospheric emissions. As the camera operated in a true imaging mode, this choice of central passbands afforded both spectral scanning [Shepherd et al., 1965] and some protection against wavelength shift due to temperature change. The specifications of the filters are listed in Table 1. For the observations of shuttle glow the Orbiter was positioned with the payload bay pointing in the nadir, with the velocity vector in the $-Y$ direction with respect to the Orbiter body $X, Y, Z$ coordinate axis system, and with the $100 \mathrm{~km}$ atmospheric layer bisecting the rear stabilizer as observed from the aft windows of the cabin. In this way it was possible to compare the shuttle glow directly with known atmospheric emissions.

For the atomic line emissions $(557.7,630.0,731.9$, and $777.4 \mathrm{~nm}$ ) this procedure is straightforward as the limb enhancement may be readily calculated. However, for the molecular emissions $\left(\mathrm{O}_{2}\right.$ atmospheric band at $762.0 \mathrm{~nm}$ and the 8-3 OH Meinel band at $730.2 \mathrm{~nm}$ ) the change of the filter capture fractions with the shift of passband, due to spatial scanning, must be considered. Studying the glow at the wavelengths of the atmospheric emissions also allows inversion of the emission profiles to determine boundary values for both temperature and species concentration [McDade and Llewellyn, 1984].

The crew activity plan for the mission afforded two opportunities to make shuttle glow measurements during two entire night passes. The first of of these was on mission day 2, when the Orbiter was at an altitude of $360 \mathrm{~km}$, and the second occurred on mission day 5 at an altitude of $230 \mathrm{~km}$. An 8-second exposure photograph from day 2 with the $630.8 \mathrm{~nm}$ filter is shown in Figure 1 and fails to reveal an obvious shuttle glow. The dimensions of the Orbiter stabilizer, on the digitized image, were carefully measured and compared with those obtained from an image taken under non-glow conditions. In practice, the equations for the surfaces of the OMS pod and the upper stabilizer were determined using a least-squares fitting routine and then used to register subsequent images. The estimated error in this procedure is \pm 2 $\mathrm{cm}$. The extension of the ring pattern throughout the entire atmosphere attests to the extended nature of the airglow emission while the ring pattern across the tail demonstrates the albedo of the shuttle. The presence of albedo away from the bright ring is due to both scattered moonlight and other airglow emissions, notably the airglow continuum and the OH Meinel bands. Similar photographs were obtained with the other filters and failed to reveal any Orbiter glow. Unfortunately, the intensifier was damaged, with a consequent loss of sensitivity, at the end of this night pass.

By comparing the airglow limb brightness with that measured on the tail of the Orbiter, upper limits for the shuttle glow at $360 \mathrm{~km}$ can be determined. These values are presented in Table 2. It should be noted that while these values are expressed in terms of a continuum brightness, the present results cannot be used to conclude that the glow is in fact a continuum at this altitude.

On mission day 5 the Orbiter was again positioned so that the velocity vector was in the $-Y$ direction and the same observing program 
was repeated. The only group of exposures, all taken with the $630.8 \mathrm{~nm}$ filter, that revealed a definitive glow were those taken after a thruster firing and before the induced glow had entirely disappeared. One of these exposures is shown in Figure 2. Through the cooperation of the entire shuttle crew it was possible to avoid exposures that included a thruster firing. A video tape, obtained from a payload bay CCTV camera operated during this entire night pass, indicates that there were only three vernier thruster firings that caused a noticeable shuttle glow during the observing period. The presence of this glow along the entire leading face of the stabilizer, except for the region shadowed by the OMS pod, indicates that at this resolution $(0.4 \mathrm{~nm})$ the thrusterinduced glow is a continuum. As for the high altitude observations, upper limits for the spacecraft glow at $230 \mathrm{~km}$ have been determined. These values are also presented in Table 2. Due to the loss of sensitivity of the intensifier, these upper limits are significantly larger than those obtained for the high-altitude observations. Attempts to correlate the induced glow photographs with the video tape are continuing although it has been noticed that each vernier thruster firing appears in three distinct parts, each less intense than its predecessor. The final brightening is close to the stabilizer and it is probably this final part that is present in Figure 2.

The width of the induced glow has been determined from the digitized image of Figure 2 to be approximately $15 \mathrm{~cm}$; this value is in reasonable agreement with the values reported by Yee and Dalgarno [1983] and Swenson et a1. [1985]. If the continuum nature of the glow observed at $630.8 \mathrm{~nm}$ also extends to the rest of the emission spectrum, then it would appear that for instruments intended to look at narrow line emissions, e.g., WAMDII and WINDII, there is no major problem from the vehicle glow. For observations over an extended spectral range this may not apply.

\section{Discussion}

If the vehicle glow, both the normal ram glow and that induced from the thruster firing, is a true continuum, it is reasonable to suppose that it arises from a recombination that forms $\mathrm{NO}_{2}$ as suggested by Swenson et al. [1985]. In Figure 3 the glow spectra of Swenson et a1. have been replotted together with those of Torr and Torr [1985] when the ISO instrument, flown on Spacelab 1, was pointing directly into the velocity vector. These latter values have been normalized to unity at the longest wavelength, i.e., $800 \mathrm{~nm}$. The continuum from NO +0 [Fontijn et a1., 1964; Paulsen et a1., 1970] and that from NO $+\mathrm{O}_{3}$ [Greaves and Garvin, 1959] have also been included in the figure. Here the values have been normalized to unity for the maximum intensity within the plotted spectral region. Recently Kenner and Ogryzlo [1984] have presented observations of an orange chemiluminescence from $\mathrm{NO}_{2}$ and these are also included in the figure. It is readily apparent that while none of these spectra exactly match the shuttle glow observations, those from Kenner and Ogryzlo [1984] are in closest agreement. This is particularly true when the uncertainty in the longer wavelength glow measurements is recognized. These latter investigators concluded that the orange glow was due to the reaction of No with vibrationally excited $\mathrm{O}_{3}$, where the latter species was formed according to the reaction: 


$$
\mathrm{O}_{2}\left(\mathrm{~A}^{3} \Sigma_{\mathrm{U}}^{+}\right)+\mathrm{O}_{2} \rightarrow \mathrm{O}_{3}^{*}+0
$$

and where the $\mathrm{O}_{2}\left(\mathrm{~A}^{3} \Sigma_{\mathrm{u}}^{+}\right)$state was formed through the heterogeneous recombination of oxygen atoms on a nickel mesh. In their analysis, Kenner and Ogryzlo [1984] concluded that the primary losses of vibrationally excited ozone were due to wall quenching and through reaction with No. However, if the measurements of the loss of vibrationally excited ozone with oxygen atoms are considered [West et a1., 1976, 1978], it appears that the analysis of Kenner and Ogryzlo [1984] could be in error. An alternate possibility is that the excited ozone state referred to by Kenner and Ogryzlo is a low lying electronic state as conjectured by McGrath et a1. [1983]. In the following analysis, we have considered both the Kenner and ogryzlo scheme and a direct reaction between $\mathrm{NO}$ and $\mathrm{O}_{2}{ }^{*}$ as suggested by Harteck and Reeves [1964]. In their analysis Kenner and Ogryzlo derived the expression:

$$
I \text { (orange glow) }=\frac{k\left[\mathrm{O}_{2}^{*}\right]\left[\mathrm{O}_{2}\right][\mathrm{NO}]}{[\mathrm{M}]}
$$

where the effective rate constant $\mathrm{k}=5 \times 10^{-13} \mathrm{~cm}^{3}$ molecule $e^{-1} \mathrm{sec}^{-1}$ and each of the other terms have their usual meaning. The concentration of excited oxygen molecules close to the nickel screen for essentially zero flow conditions, would be given by:

$$
\left[0_{2}^{*}\right]=\frac{\xi[0]}{k_{1}[0]+k_{2}\left[0_{2}\right]+A}
$$

where $\xi$ is the efficiency of the surface recombination; $k_{1}$ [0] represents the loss rate of $\mathrm{O}_{2} *$ through $0 ; \mathrm{k}_{2}\left[\mathrm{O}_{2}\right]$ is the loss rate through $\mathrm{O}_{2}$; and $A$ is the radiative loss. For the model atmosphere shown in Table 3 , the concentration of $\mathrm{O}_{2} *$ is equal to $\xi \times 10^{\prime \prime}$ at all altitudes. If the surface layer of $\mathrm{O}_{2}^{*}$ does not build up during the flight, then the production rate would equal the loss rate from the surface. Thus the production rate of orange glow emitters is equal to $2 \times 10^{3} \xi$ [NO] at 200 $\mathrm{km}$ and $3.6 \times 10^{\prime} \xi$ [NO] at $300 \mathrm{~km}$. Hence the surface brightness over the entire spectrum at $200 \mathrm{~km}$ is $260 \xi \mathrm{kR}$ and $9.3 \xi \mathrm{R}$ at $300 \mathrm{~km}$. For any reasonable value of the efficiency [Black and Slanger, 1981] this is unable to match the glow intensity reported by Mende et al. [1984] or the upper limits obtained here.

An alternative approach is to consider the direct reaction of $\mathrm{O}_{2} *$ and NO as postulated by Harteck and Reeves [1964]. In this case we have a production rate expression given by:

$$
\text { I (orange glow) }=\frac{\xi[0] k_{3}[\mathrm{NO}]}{\mathrm{k}_{1}[0]+\mathrm{k}_{2}\left[\mathrm{O}_{2}\right]+\mathrm{A}} .
$$

Under these conditions at $200 \mathrm{~km}$, the surface brightness is equal to $9 \mathrm{x}$ $10^{24} \xi \mathrm{k}_{3}$ and $1 \times 10^{2} \xi \mathrm{k}_{3}$ at $300 \mathrm{~km}$. If $\mathrm{k}_{3}$ is gas kinetic and $\xi=10^{-4}$ the effective surface brightness is $90 \mathrm{kR}$ at $200 \mathrm{~km}$ and $100 \mathrm{R}$ at $300 \mathrm{~km}$. These values do not contradict the presently available measurements although it should be noted that the glow forming reaction is in the gas phase. The surface simply provides a source of $\mathrm{O}_{2} *$ and an opportunity for the effective No concentration to be doubled. The high speed of the emitting molecules is simply due to the mechanics of the collision. The 
thruster glow would of course follow both this reaction and the normal NO + 0 reaction. This latter reaction would deplete [0] so that the normal shuttle glow would be enhanced; the loss of $\mathrm{O}_{2}^{*}$ through

collisions with 0 is decreased. However, after the thruster firing, the $\mathrm{O}_{2}{ }^{*}$ concentration on the shuttle surface would be reduced and the vehicle glow could be reduced, at least for a short time. As Ogryzlo and Slanger (private communications, 1985) have noted, different materials have different efficiences as catalysts for the surface recombination of oxygen atoms, so that it is to be expected that vehicle glow is material dependent.

An alternative hypothesis has been presented by Swenson et al. [1985] who suggested that the glow recombination reactions essentially followed the surface formation of an NO monolayer. However, the departure of the observed glow spectrum from that of NO +0 allows us to question that mechanism. A mechanism in which oxygen atoms adsorbed on the surface react with impacting No molecules and then are extracted from the surface has been suggested by Thrush et al. [1968]. Although such a mechanism could indeed shift the $\mathrm{NO}_{2}$ spectrum to longer wavelengths, Kenner and Ogryzlo [1984] have shown that such a process is unnecessary for the formation of the orange glow. It should also be noted that a potential source of enhanced NO concentration could be the reaction between incident $\mathrm{N}$ atoms and $\mathrm{O}_{2}{ }^{*}$ molecules residing on the surface.

Acknowledgments. We wish to acknowledge the assistance provided by B.H. Long, G.R. Swenson, and G.J. Buttner in the present work. This experiment has been supported by the Canada Centre for Space Science of the National Research Council of Canada; the Lockheed Palo Alto Research Laboratory; and the Universities Space Research Association.

\section{References}

Black, G., and T.G. Slanger, Production of $\mathrm{O}_{2}\left(\mathrm{a}^{\prime} \Delta \mathrm{g}\right)$ by oxygen atom recombination on a pyrex surface, J. Chem. Phys., 74, 6517-6519, 1981.

Fontijn, A., C.B. Meyer, and H.I. Schiff, Absolute quantum yield measurements of the NO-O reaction and its use as a standard for the chemiluminescent reactions, J. Chem Phys., 40, 64-70, 1964.

Greaves, J.C., and D. Garvin, Chemically induced molecular excitation: Excitation spectrum of the nitric oxide-ozone system, J. Chem. Phys., $\underline{30}, 348-349,1959$.

Harteck, P., and R.R. Reeves, Formation and reaction of the excited $\mathrm{O}_{2}\left(\mathrm{~A}^{3} \Sigma^{+}\right)$molecule, Disc. Faraday Soc., 37, 82-86, 1964.

Kenda11, D.J.W., R.L. Gattinger, R. Wlochowicz, M. Garneau, G.J. Buttner, S. Mende, G.R. Swenson, E.J. Llewellyn, W.A. Gault, G.G. Shepherd, B.H. Solheim, and L.L. Cogger, OGLOW - An experiment to measure Orbiter and Earth optical emissions, Canad. Aeronaut. Space J., in press, 1985.

Kenner, R.D., and E.A. Ogryzlo, Orange chemiluminescence from $\mathrm{NO}_{2}, \mathrm{~J}$. Chem. Phys., 80, 1-6, 1984.

McDade, I.C., and E.J. Llewellyn, Atomic oxygen concentrations in the auroral ionosphere, Geophys. Res. Lett., 11, 247-250, 1984.

McGrath, W.D., J.M. Maguire, A. Thompson, and J. Trocha-Grimshaw, The production of electronically excited ozone by flash irradiation, Chem. Phys. Lett., 102, 59-63, 1983. 
Mende, S.B., P.M. Banks, and D.A. Klingelsmith, III, Observations of orbiting vehicle induced luminosities on the STS-8 mission, Geophys. Res. Lett., 11, 527-530, 1984.

Paulsen, D.E., W.F. Sheridan, and R.E. Huffman, Thermal and recombination emission of $\mathrm{NO}_{2}, \mathrm{~J}$. Chem. Phys., 53, 647-658, 1970.

Shepherd, G.G., C.W. Lake, J.R. Miiller, and L.L. Cogger, A spatial spectral scanning technique for the Fabry-Perot spectrometer, Appl. Opt., 4, 267-272, 1965.

Shepherd, G.G., W.A. Gault, D.W.Miller, Z. Pasturczyk, S.F. Johnston, J.W. Haslett, D.J.W. Kenda11, and J.R. Wimperis, WAMDII: Wide Angle Michelson Doppler Imaging Interferometer for Spacelab, Appl. Opt., in press, 1985.

Swenson, G.R., S.B. Mende, and K.S. Clifton, Ram vehicle glow spectrum: Implication of $\mathrm{NO}_{2}$ recombination continuum, Geophys. Res. Lett., 12 , 97-100, 1985.

Thrush, B.A., C.J. Halstead, and A. McKenzie, Chemiluminescence in gases: Reactions yielding electronically excited sulfur dioxide, J. Phys. Chem., 72, 3711-3714, 1968.

Torr, M.R., and D.G. Torr, A preliminary spectroscopic assessment of the Spacelab 1/shuttle optical environment, J. Geophys. Res., 90, 1683$1690,1985$.

West, G.A., R.E. Weston, and G.W. Flynn, Deactivation of vibrationally excited ozone by $O\left({ }^{3} P\right)$ atoms, Chem. Phys. Lett., 42, 489-493, 1976.

West, G.A., R.E. Weston, and G.W. Flynn, The influence of reactant vibrational excitation on the $O\left({ }^{3} \mathrm{P}\right)+\mathrm{O}_{3}+$ bimolecular reaction rate, Chem. Phys. Lett., 51, 429-433, 1978.

Yee, J.H., and A. Dalgarno, Radiative lifetime analysis of the shuttle optical glow, AIAA-83-CP838, AIAA Shuttle Environment and Operations Meeting, 191-196, 1983. 


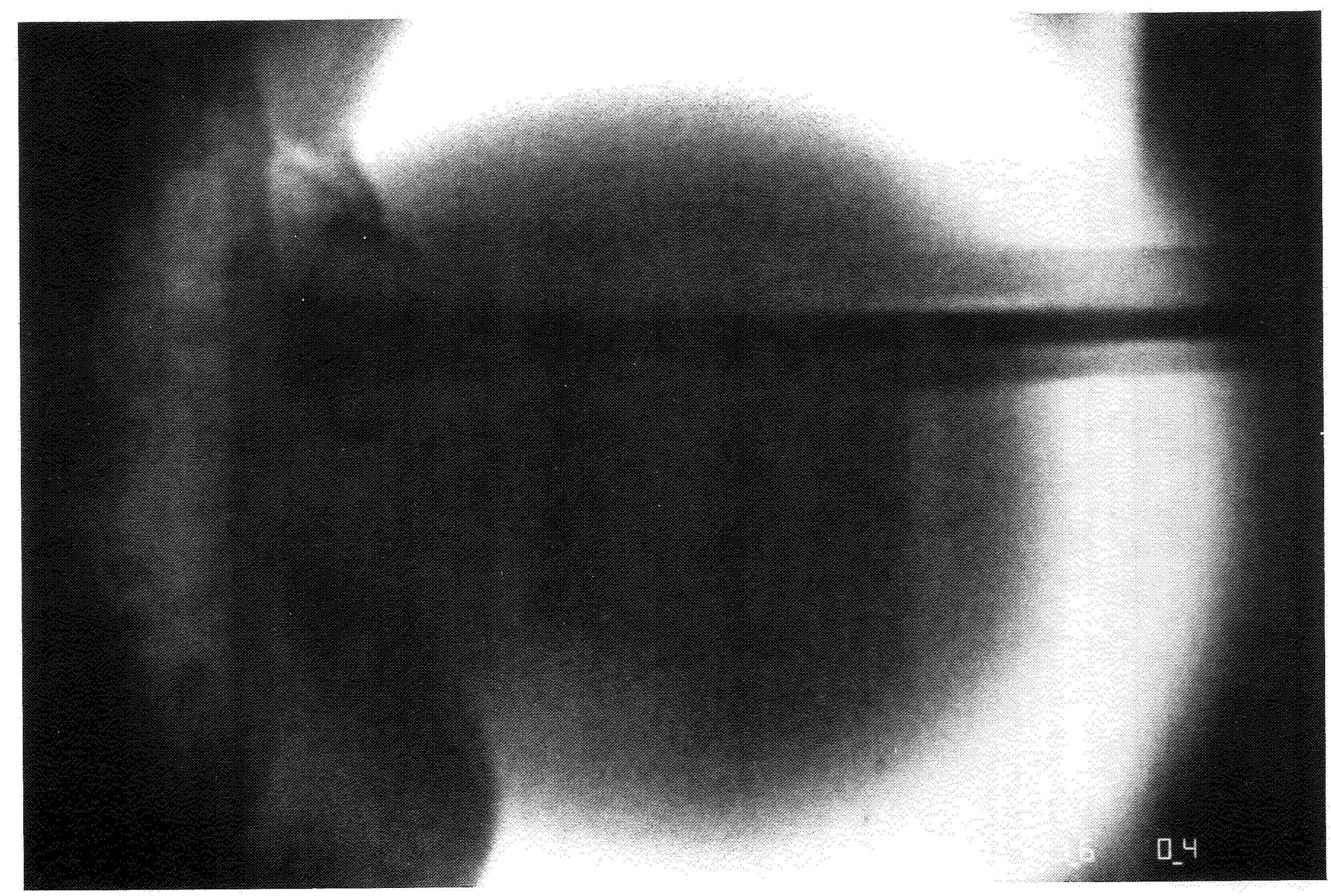

Fig. 1. Ram glow photograph of the rear stabilizer taken with the $630.8 \mathrm{~nm}$ filter at $360 \mathrm{~km}$ altitude; exposure time $8 \mathrm{sec}$. 
Fig. 2. Ram glow photograph of the rear stabilizer taken with the $630.8 \mathrm{~nm}$ filter at $230 \mathrm{~km}$ altitude following a thruster firing. 


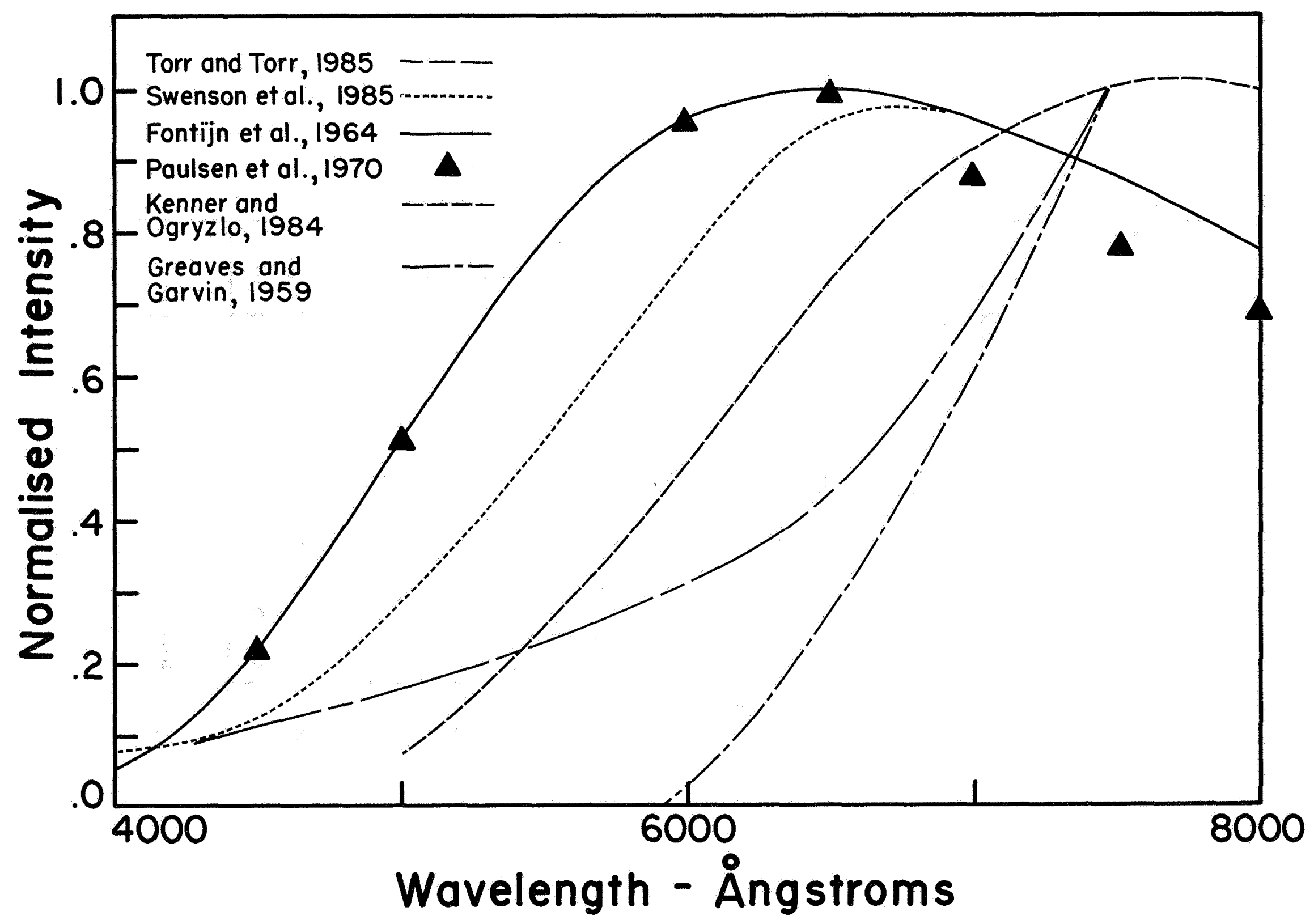

Fig. 3. Comparison of Orbiter glow and $\mathrm{NO}_{2}$ continuum spectra. 
TABLE 1. FILTER SPECIFICATIONS

\begin{tabular}{|c|c|c|c|c|c|}
\hline $\begin{array}{l}\text { Filter } \\
\text { No. }\end{array}$ & Emission & $\underset{n m}{\text { Wave length }}$ & $\begin{array}{c}\text { Center } \\
\text { Wavelength } \\
\text { nm }\end{array}$ & $\underset{n m}{\text { Bandwidth }}$ & $\begin{array}{c}\text { Peak } \\
\text { Transmittance } \\
\text { percent }\end{array}$ \\
\hline F 1 & $0{ }^{1} D-{ }^{1} S$ & 557.735 & 558.30 & 0.40 & 44 \\
\hline F2 & $0{ }^{3} P-{ }^{1} D$ & 630.031 & 630.78 & 0.31 & 58 \\
\hline F3 & $\begin{aligned} \text { Meine } 1 & Q_{1}(1) \\
\mathrm{OH}(8,3) & Q_{1}(2) \\
& Q_{1}(3)\end{aligned}$ & $\begin{array}{l}727.840 \\
728.638 \\
729.780\end{array}$ & 730.08 & 0.38 & 52 \\
\hline F6 & $\mathrm{O}^{+}{ }^{2} \mathrm{D}-{ }^{2} \mathrm{P}$ & $\begin{array}{l}731.984 \\
\text { mean-doublet }\end{array}$ & 733.18 & 0.40 & 52 \\
\hline F4 & $\begin{array}{rr}\text { Atm } & { }^{P_{Q}(11)} \\
0_{2}(0-0) & P_{P(11)}\end{array}$ & $\begin{array}{l}763.959 \\
764.071\end{array}$ & 764.24 & 0.41 & 47 \\
\hline F5 & $03 s^{5} s-3 p^{5} p$ & $\begin{array}{l}777.194 \\
777.417 \\
777.539\end{array}$ & 778.42 & 0.40 & 51 \\
\hline
\end{tabular}


TABLE 2. UPPER BOUNDS FOR SHUTTLE GLOW INTENSITY ON MISSION 41-G

\section{Wavelength}

$\mathrm{nm}$

557.7

630.0

730.2

762.0

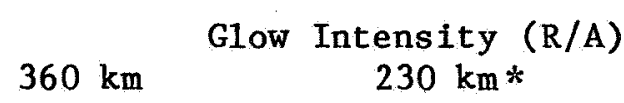

$<40$

$<100$

$<200$

$<200$

$<300$
$222 \mathrm{~km}(\mathrm{STS}-8)$

150

300

400

550

* These values have been modified from those presented at the workshop by reason of more recent analysis.

TABLE 3. MODEL ATMOSPHERE FOR GLOW ANALYSIS

$\begin{array}{lcccc}\begin{array}{c}\text { Altitude } \\ \mathrm{km}\end{array} & \begin{array}{c}{[\mathrm{O}]} \\ \mathrm{cm}^{-3}\end{array} & \begin{array}{c}{[\mathrm{NO}]} \\ \mathrm{cm}^{-3}\end{array} & \begin{array}{c}{\left[\mathrm{O}_{2}\right]} \\ \mathrm{cm}^{-3}\end{array} & \begin{array}{l}{[\mathrm{M}]} \\ \mathrm{cm}^{-3}\end{array} \\ 200 & 3 \times 10^{9} & 5 \times 10^{5} & 4 \times 10^{8} & 6 \times 10^{9} \\ 300 & 4 \times 10^{8} & 10^{3} & 6 \times 10^{6} & 5 \times 10^{8}\end{array}$

